\title{
Expanding the indication for sutureless aortic valve replacement to patients with mitral disease
}

\author{
Tam Hoang Minh, MD, Amine Mazine, MD, Ismail Bouhout, MD, Ismail El-Hamamsy, MD, PhD, \\ Michel Carrier, MD, MBA, Denis Bouchard, MD, PhD, and Philippe Demers, MD, MSc
}

Objectives: To review our experience with sutureless aortic valve replacement (AVR) in the setting of concomitant mitral valve (MV) surgery and discuss the technical considerations.

\begin{abstract}
Methods: Between January 2012 and March 2013, 10 patients underwent sutureless AVR with the Perceval prosthesis in the setting of concomitant mitral disease. Five patients underwent MV repair, 4 underwent MV replacement, and 1 had a previously implanted mechanical mitral prosthesis.

Results: The median age was 79 years and 7 patients $(70 \%)$ were male. Median logistic EuroSCORE II was $6.2 \%$. All valves were successfully implanted with no 30-day mortality. There was no residual aortic paravalvular leak. Two patients had from third-degree atrioventricular block requiring permanent pacemaker implantation. At a mean follow-up of $8 \pm 4$ months (range, 2-16 months), the overall survival was $80 \%$ with 2 non-valve-related deaths and the mean transaortic gradient and aortic valve area had improved to $11.1 \pm 4.6 \mathrm{~mm} \mathrm{Hg}$ and $1.5 \pm 0.3 \mathrm{~cm}^{2}$, respectively. There was no evidence of mitral dysfunction in any patient.

Conclusions: In our experience, sutureless AVR in the setting of concomitant mitral surgery is a feasible and reproducible procedure. Elderly patients undergoing multiple valve surgery present a higher operative risk, therefore extending the indication for sutureless AVR to patients with concomitant mitral disease could greatly benefit this specific population. (J Thorac Cardiovasc Surg 2014;148:1354-9)
\end{abstract}

Sutureless aortic valve replacement (AVR) is an emerging alternative to standard AVR in elderly high-risk surgical patients. Potential advantages include shorter aortic crossclamp times and easier access for minimally invasive surgery. Several case series have shown good early clinical and hemodynamic outcomes with the use of sutureless prostheses. ${ }^{1-3}$ However, despite promising initial clinical results, the indications for sutureless AVR are still being refined. ${ }^{4}$

Patients undergoing multiple valve surgery present a higher operative risk, partly as a result of prolonged periods of cardiopulmonary bypass and myocardial ischemia. ${ }^{5}$ These patients could theoretically benefit from the reduction in crossclamp times associated with sutureless AVR. However, the presence of a previously implanted mitral prosthesis or the need for concomitant mitral valve (MV) surgery are generally viewed as contraindications to

From the Department of Cardiovascular Surgery, Montreal Heart Institute and Université de Montréal, Montreal, Quebec, Canada.

This study was funded by the Montreal Heart Institute's Department of Cardiovascular Surgery. No extramural funding supported this work.

Disclosures: Denis Bouchard has received lecture fees from Sorin. All other authors nothing to disclose with regard to commercial support.

T.H. Minh and A. Mazine contributed equally to this work and share first authorship. Received for publication Sept 26, 2013; revisions received Nov 15,2013; accepted for publication Dec 12, 2013.

Address for reprints: Philippe Demers, MD, MSc, 5000 Belanger St, Montréal, Quebec, Canada, H1T 1C8 (E-mail: philippe.demers@icm-mhi.org). 0022-5223/\$36.00

Copyright $₫ 2014$ Published by Elsevier Inc. on behalf of The American Association for Thoracic Surgery

http://dx.doi.org/10.1016/j.jtcvs.2013.12.061 sutureless AVR, because of the potential risk of interference between the 2 valves at the level of the aorto-mitral continuity.

We assessed the hypothesis that sutureless AVR can be safely performed in patients requiring concomitant MV surgery. We review our experience with sutureless AVR in this setting and describe the technical considerations.

\section{METHODS}

Between June 2011 and May 2013, 120 patients with severe aortic stenosis underwent sutureless AVR using the Perceval S prosthesis (Sorin, Saluggia, Italy). Ten of these patients had concomitant MV disease.

The Perceval S sutureless valve is a new-generation aortic bioprosthesis and is composed of bovine pericardium mounted within a superelastic alloy frame. The device can be collapsed through a dedicated device and deployed using a specific delivery system.

Implantation of the prosthesis was approved by the Canadian Department of Health and Welfare (Ottawa, Canada) for each patient. Informed written consent was obtained from all patients and the study was approved by our institution's local ethics committee. All patients were prospectively followed at our center's dedicated Valve Clinic.

Statistical analyses were performed using Statistical Package for Social Sciences (SPSS) v20 (SPSS, Inc, Chicago, Ill). Continuous variables are presented as the median (range) and categorical variables are presented as the frequency $(\%)$. Operative mortality was defined as death occurring within 30 days of surgery or during the index hospitalization. Improvements in mean aortic gradient and aortic valve area were assessed with the Wilcoxon signed rank test.

\section{Surgical Technique}

The technique for implantation of the Perceval sutureless prosthesis has been described elsewhere ${ }^{2,4}$ and is briefly summarized here. All procedures were performed via median sternotomy under moderately hypothermic 


\section{Abbreviations and Acronyms \\ AVR = aortic valve replacement \\ LVOT $=$ left ventricular outflow tract \\ $\mathrm{MV}=$ mitral valve \\ NYHA $=$ New York Heart Association \\ TAVI $=$ Transcatheter aortic valve implantation}

$\left(32^{\circ} \mathrm{C}\right)$ cardiopulmonary bypass and cardioplegic arrest. A transverse aortotomy was performed approximately $3.5 \mathrm{~cm}$ above the level of the aortic annulus. The native valve was removed and moderate decalcification of the annulus was performed to obtain a homogeneous circular surface. The aortic annulus was then measured and the appropriate prosthesis size was selected. During the study period, the extralarge prosthesis $(27 \mathrm{~mm})$ was not yet available. At this stage, standard left auriculotomy was performed and the MV was assessed. It was either repaired $(n=5)$ or replaced using a bioprosthesis $(n=4)$. After closure of the auriculotomy, the aortic annulus was resized to ensure consistency of the initial measurements. The sutureless valve selected was then guided into its correct position using a specific delivery system and three 4-0 polypropylene guiding sutures. These sutures were passed through the aortic annulus at the nadir of each aortic cusp. The valve was then deployed and the delivery system and sutures were removed. After deployment, a dedicated balloon was inserted into the prosthesis and expanded for 30 seconds at a pressure of $4 \mathrm{~atm}$. Once correct positioning of the valve was confirmed, the ascending aorta was closed in a standard fashion. Concomitant tricuspid valve repair was required in 2 patients. Tricuspid repair was performed before sutureless valve deployment to avoid distorting the aortic annulus during exposure.

\section{RESULTS}

\section{Patient Baseline Characteristics}

The median age of the patients was 79 years (range, 73-85 years). Seven patients were male. The baseline characteristics of the patients are summarized in Table 1 . Four patients were obese (body mass index $>30 \mathrm{~kg} / \mathrm{m}^{2}$ ). Sixty percent of patients were in New York Heart Association (NYHA) class III or IV. Median logistic EuroSCORE II predicted mortality was $6.2 \%$ (range, $2.1 \%-16.4 \%$ ). No patient had a permanent pacemaker before surgery. The median preoperative left ventricular ejection fraction was $60 \%$ (range, $35 \%-65 \%$ ). The median preoperative pulmonary artery systolic pressure was $43 \mathrm{~mm} \mathrm{Hg}$ (range, 36-65 $\mathrm{mm} \mathrm{Hg}$ ); 3 patients had severe pulmonary hypertension $(>55 \mathrm{~mm} \mathrm{Hg})$. One patient had a $29-\mathrm{mm}$ Carbomedics (Sorin) mechanical mitral prosthesis that had been implanted 21 years earlier. The mean transmitral gradient across the prosthesis was $3.1 \mathrm{~mm} \mathrm{Hg}$ with an MV area of $2.8 \mathrm{~cm}^{2}$. The median length of the aorto-mitral continuity, as measured by preoperative transesophageal echocardiography, was $11 \mathrm{~mm}$ (range, 8-14 $\mathrm{mm}$ ).

\section{Operative Details}

The procedural details are summarized in Table 2. Successful implantation of the sutureless aortic prosthesis was achieved in all patients. Five patients underwent concomitant MV plasty and 4 underwent concomitant biological MV replacement. Other concomitant procedures included aortic commissuroplasty $(\mathrm{n}=2)$, septal myectomy $(n=2)$, tricuspid valve repair $(n=2)$, maze radiofrequency procedure $(n=2)$, coronary artery bypass graft $(n=1)$, and atrial septal defect closure $(n=1)$. Seventy percent of patients received a medium-sized $(23 \mathrm{~mm})$ sutureless aortic prosthesis.

All patients who underwent MV repair received an annuloplasty. The first patient received a complete Carpentier-Edwards Physio ring (Edwards Lifesciences, Irvine, Calif); the remaining 4 patients received a partial Annuloflex ring (Sorin). Ring size was $34 \mathrm{~mm}$ and $36 \mathrm{~mm}$ in 3 and 2 patients, respectively. Other repair techniques included quadrangular resection $(\mathrm{n}=2)$, chordal transposition $(\mathrm{n}=1)$, and commissuroplasty $(\mathrm{n}=2)$.

All patients who underwent MV replacement received a 27-mm bioprosthesis. One patient received a Perimount Plus valve (Edwards Lifesciences) and 3 received a Magna-Ease valve (Edwards Lifesciences).

Intraoperative redeployment of the sutureless aortic prosthesis was necessary in 4 patients. In 2 of these cases, the diameter of the aortic annulus was greater than $25 \mathrm{~mm}$ and both patients had to undergo aortic commissuroplasty to ensure a tight fit of the prosthesis. In the remaining 2 cases, there was supraannular malposition of the prosthesis. In the 4 patients requiring redeployment, the sutureless valve was easily removed using the $\chi$-movement technique ${ }^{6}$ and subsequently reimplanted. In 1 case, the aorta had to be reclamped and the heart rearrested to redeploy the prosthesis.

On the control intraoperative transesophageal echocardiograms, there were no cases of aortic paravalvular regurgitation. In addition, all patients showed aortic insufficiency of $1 / 4$ or less and mitral insufficiency of $1 / 4$ or less.

\section{Perioperative Outcomes}

There were no 30-day mortalities. No postoperative valve migration was observed and no patient had a stroke or myocardial infarction. During the postoperative period, 1 patient had bleeding requiring reoperation and 2 patients presented transient acute renal failure $(>50 \%$ increase in the serum creatinine concentration). Postoperative delirium occurred in $40 \%$ of patients. Two patients had third-degree atrioventricular block requiring permanent pacemaker implantation. Eight patients received at least 1 blood transfusion (median, 2 red blood cell units per patient). The median postoperative intensive care unit length of stay was 4 days (range, 0-14 days).

The predischarge echocardiographic results are presented in Table 3 . The mean aortic valve area increased from $1.0 \pm 0.3 \mathrm{~cm}^{2}$ (range, $0.6 ; 1.8 \mathrm{~cm}^{2}$ ) to $1.6 \pm 0.4 \mathrm{~cm}^{2}$ 
TABLE 1. Baseline preoperative patient characteristics

\begin{tabular}{|c|c|c|c|c|c|c|c|c|c|c|c|}
\hline Patient no. & $\begin{array}{c}\text { Age } \\
\text { (years) }\end{array}$ & Sex & $\begin{array}{c}\text { LVEF } \\
(\%) \\
\end{array}$ & $\begin{array}{c}\text { PASP } \\
(\mathrm{mm} \mathrm{Hg}) \\
\end{array}$ & $\begin{array}{c}\text { NYHA } \\
\text { class }\end{array}$ & $\begin{array}{c}\text { Logistic } \\
\text { EuroSCORE II } \\
\end{array}$ & $\begin{array}{c}\text { AV mean gradient } \\
(\mathrm{mm} \mathrm{Hg})\end{array}$ & $\operatorname{AVA}\left(\mathrm{cm}^{2}\right)$ & $\begin{array}{c}\text { AI } \\
\text { grade }\end{array}$ & Mitral disease & $\begin{array}{r}\text { Mitro-aortic } \\
\text { distance }(\mathbf{m m})\end{array}$ \\
\hline 1 & 81 & $\mathrm{~F}$ & 65 & 36 & II & 2.1 & 71.9 & 0.66 & 1 & MI (3/4) & 14 \\
\hline 2 & 83 & M & 35 & 61 & III & 16.4 & 25.2 & 1.21 & 1 & MI (3/4) & 11 \\
\hline 3 & 83 & M & 60 & 42 & II & 4.1 & 22.0 & 0.80 & 0 & MI (3/4) & 9 \\
\hline 4 & 85 & M & 65 & 39 & III & 4.6 & 23.8 & 1.09 & 1 & MI (4/4) & 14 \\
\hline 5 & 78 & $\mathrm{~F}$ & 43 & 65 & II & 6.8 & 7.6 & 1.75 & 2 & MI (3/4) & 8 \\
\hline 6 & 74 & M & 60 & 65 & III & 5.61 & 12.7 & 1.20 & 1 & $\begin{array}{l}\text { MI }(3 / 4), \text { MS } \\
\text { (MVA 0.62, MG 17.5) }\end{array}$ & 10 \\
\hline 7 & 79 & M & 65 & 43 & III & 6.9 & 26.9 & 0.96 & 2 & MI (3/4) & 11 \\
\hline 8 & 73 & $\mathrm{~F}$ & 60 & 42 & IV & 4.9 & 46.0 & 0.59 & 0 & MS (MVA 1.1, MG 7) & 14 \\
\hline 9 & 78 & M & 55 & 47 & III & 7.1 & 30.4 & 0.89 & 1 & MS (MVA 1.7, MG 6.4) & 11 \\
\hline 10 & 75 & M & 50 & 38 & II & 10.5 & 39.3 & 0.80 & 2 & Previous MVR & 10 \\
\hline
\end{tabular}

$L V E F$, Left ventricular ejection fraction; $P A S P$, pulmonary artery systolic pressure; $N Y H A$, New York Heart Association; $A V$, aortic valve; $A V A$, aortic valve area; $A I$, aortic insufficiency; $F$, female; $M$, male; $M I$, mitral insufficiency; $M S$, mitral stenosis; $M V A$, mitral valve area; $M G$, mean gradient; $M V R$, mitral valve replacement.

(range, 1.1-2.3 $\left.\mathrm{cm}^{2}\right)(P=.01)$ with a decrease in mean transaortic pressure gradient from $30.6 \pm 18.4 \mathrm{~mm} \mathrm{Hg}$ (range, 7.6-71.9 $\mathrm{mm} \mathrm{Hg}$ ) to $12.3 \pm 4.8 \mathrm{~mm} \mathrm{Hg}$ (range, 5.8-21.4 mm Hg) $(P=.01)$. Aortic insufficiency was mild or less in all patients with no paravalvular leak. The mean MV area was $1.8 \pm 0.5 \mathrm{~cm}^{2}$ (range, 1.2$2.9 \mathrm{~cm}^{2}$ ) and the mean transmitral pressure gradient was $4.8 \pm 1.8 \mathrm{~mm} \mathrm{Hg}$ (range, 2.1-7.8 mm Hg). One patient had moderate mitral insufficiency. There was no evidence of interference between the aortic and mitral prostheses in any patient.

\section{Early Follow-up}

At a mean follow-up of $8 \pm 4$ months (range, 2 to 16 months), there were 2 non-valve-related deaths, giving an overall survival of $80 \%$. One patient died of hemorrhagic shock secondary to angiodysplasia 2 months after surgery; the other patient died of pneumonia 9 months after the operation. Among surviving patients, NYHA functional class at last follow-up was I/IV in 7 patients and II/IV in 1 patient.

A follow-up echocardiogram was obtained in all surviving patients at a mean of $8 \pm 4$ months (range, 3-15 months). There was no structural aortic valve deterioration and no evidence of paravalvular leak. The mean transaortic pressure gradient was $11.1 \pm 4.6 \mathrm{~mm}$ $\mathrm{Hg}$ (range, $5.5-21.3 \mathrm{~mm} \mathrm{Hg}$ ) and the mean aortic valve area was $1.5 \pm 0.3 \mathrm{~cm}^{2}$ (range, $1.0-2.0 \mathrm{~cm}^{2}$ ) (Figure 1). There was no evidence of mitral dysfunction in any patient.

TABLE 2. Periprocedural data

\begin{tabular}{|c|c|c|c|c|c|c|c|}
\hline Patient no. & $\begin{array}{c}\text { Perceval } \\
\text { prosthesis } \\
\text { size }(\mathbf{m m}) \\
\end{array}$ & $\begin{array}{c}\text { Intervention on } \\
\text { mitral valve } \\
\end{array}$ & $\begin{array}{c}\text { Mitral ring/prosthesis } \\
\text { implanted }\end{array}$ & $\begin{array}{c}\text { Need for } \\
\text { Perceval } \\
\text { redeployment }\end{array}$ & $\begin{array}{c}\text { Concomitant } \\
\text { procedure }\end{array}$ & $\begin{array}{c}\text { Crossclamp } \\
\text { time (min) } \\
\end{array}$ & $\begin{array}{c}\text { CPB } \\
\text { time (min) }\end{array}$ \\
\hline 1 & 25 & Annuloplasty + QR P1 & Physio (34 mm) & No & ASD closure & 59 & 66 \\
\hline 2 & 25 & $\begin{array}{l}\text { Annuloplasty }+ \text { posterior } \\
\text { commissuroplasty }\end{array}$ & Annuloflex $(36 \mathrm{~mm})$ & Yes & $\begin{array}{l}\text { Maze }+ \text { aortic } \\
\text { commissuroplasty }\end{array}$ & 106 & 150 \\
\hline 3 & 23 & Annuloplasty & Annuloflex (34 mm) & Yes & $\mathrm{CABG}$ & 73 & 93 \\
\hline 4 & 23 & $\begin{array}{l}\text { Annuloplasty }+ \text { anterior } \\
\text { and posterior } \\
\text { commissuroplasty }\end{array}$ & Annuloflex (36 mm) & No & - & 81 & 95 \\
\hline 5 & 25 & $\begin{array}{l}\text { Annuloplasty }+ \text { QR P2 + } \\
\text { Chordal Transposition } \\
\text { P2 } \rightarrow \text { A2 }\end{array}$ & Annuloflex $(34 \mathrm{~mm})$ & Yes & Aortic commissuroplasty & 75 & 84 \\
\hline 6 & 23 & Biological MVR & Magna-Ease $(27 \mathrm{~mm})$ & Yes & / & 100 & 113 \\
\hline 7 & 23 & Biological MVR & Magna-Ease $(27 \mathrm{~mm})$ & No & MAZE + septal myectomy & 78 & 90 \\
\hline 8 & 23 & Biological MVR & Perimount Plus (27 mm) & No & l & 129 & 161 \\
\hline 9 & 23 & Biological MVR & Magna-Ease $(27 \mathrm{~mm})$ & No & $\begin{array}{l}\text { TV repair }+ \text { septal } \\
\text { myectomy }\end{array}$ & 97 & 112 \\
\hline 10 & 23 & $\begin{array}{l}\text { None (previous } \\
\text { mechanical MVR) }\end{array}$ & Carbomedics $(29 \mathrm{~mm}) 1992$ & No & TV repair & 32 & 63 \\
\hline
\end{tabular}

$\overline{C P B}$, Cardiopulmonary bypass; $Q R$, quadrangular resection; $A S D$, atrial septal defect; $C A B G$, coronary artery bypass graft; $M V R$, mitral valve replacement; $T V$, tricuspid valve. 
TABLE 3. Early postoperative echocardiographic results

\begin{tabular}{|c|c|c|c|c|c|c|c|}
\hline Patient no. & AV mean gradient $(\mathrm{mm} \mathrm{Hg})$ & $\operatorname{AVA}\left(\mathrm{cm}^{2}\right)$ & iAVA $\left(\mathrm{cm}^{2} / \mathrm{m}^{2}\right)$ & AI grade & MV mean gradient (mm Hg) & $\operatorname{MVA}\left(\mathrm{cm}^{2}\right)$ & MI grade \\
\hline 1 & 13.8 & 1.81 & 1.06 & 0 & 6.0 & 2.2 & 0 \\
\hline 2 & 15.2 & 1.21 & 0.70 & 1 & 5.6 & 1.25 & 0 \\
\hline 3 & 16.6 & 1.10 & 0.66 & 0 & 4.4 & 1.64 & 0 \\
\hline 4 & 10.6 & 1.71 & 1.12 & 1 & 3.0 & 1.35 & 2 \\
\hline 5 & 13.0 & 1.67 & 0.99 & 0 & 2.1 & 2.19 & 0 \\
\hline 6 & 5.8 & 2.3 & 1.52 & 0 & 3.2 & 2.9 & 0 \\
\hline 7 & 5.9 & 1.7 & 1.01 & 0 & 3.6 & 1.8 & 0 \\
\hline 8 & 21.4 & 1.52 & 0.68 & 1 & 7.8 & 2.03 & 0 \\
\hline 9 & 8.9 & 1.33 & 0.76 & 0 & 6.9 & 1.18 & 1 \\
\hline 10 & 11.6 & 1.9 & 1.10 & 0 & 5.5 & 1.87 & 0 \\
\hline
\end{tabular}

$A V$, Aortic valve; $A V A$, aortic valve area; $i A V A$, indexed aortic valve area; $A I$, aortic insufficiency; $M V$, mitral valve; $M V A$, mitral valve area; $M I$, mitral insufficiency.

\section{DISCUSSION}

Sutureless prosthetic heart valves were first introduced half a century ago. ${ }^{7}$ In recent years, the concept was revisited and a new generation of sutureless aortic bioprostheses was developed to serve as an alternative to standard surgical AVR and transcatheter aortic valve implantation (TAVI) in high-risk patients and those requiring multiple concomitant procedures. However, sutureless AVR in the setting of concomitant MV replacement has yet to be described. The presence of a prosthetic valve in the mitral position is generally regarded as a contraindication to sutureless AVR because of concerns that the mitral device may (1) alter the three-dimensional structure of the aortic root and left ventricular outflow tract (LVOT), thus interfering with the deployment and stability of the sutureless prosthesis; and/or (2) directly interfere with the aortic device.

There have been several reports of patients with functioning mitral prostheses undergoing successful TAVI using both the CoreValve (Medtronic CV, Santa Rosa, Calif) and the SAPIEN valve (Edwards Lifesciences). ${ }^{8-12}$ Because sutureless aortic bioprostheses are similar in design to the devices used for TAVI, we believed that these results could also be achieved using sutureless aortic valves.
The present series demonstrates that implantation of a sutureless aortic bioprosthesis is feasible in patients undergoing concomitant MV repair or replacement. However, some technical challenges exist. These technical concerns relate to the proximity and potential interaction of the aortic and mitral prostheses at the level of the aorto-mitral continuity. The anatomic aorto-mitral curtain is a fibrous structure that connects the aortic annulus to the anterior leaflet of the MV. The length of this continuity was measured in all patients using transesophageal echocardiography. The importance of this measurement lies in the fact that a narrow aorto-mitral continuity has been associated with procedural failure in TAVI as a result of direct prosthesis interference ${ }^{13}$ and aortic device shift during deployment. ${ }^{8}$ A recently published study concluded that, in patients with a mechanical mitral prosthesis, a minimal aorto-mitral curtain length of $9 \mathrm{~mm}$ should be confirmed before TAVI to minimize the risk of interference between the aortic and mtiral prostheses. ${ }^{14}$ In the present series, no interference between the aortic and mitral valves was observed despite the fact that in 1 patient, the aorto-mitral continuity was measured at $8 \mathrm{~mm}$ (Figure 2). The cut-off point in terms of minimal aorto-mitral length is probably lower for sutureless AVR as the Perceval prosthesis protrudes less in the LVOT than the CoreValve. In
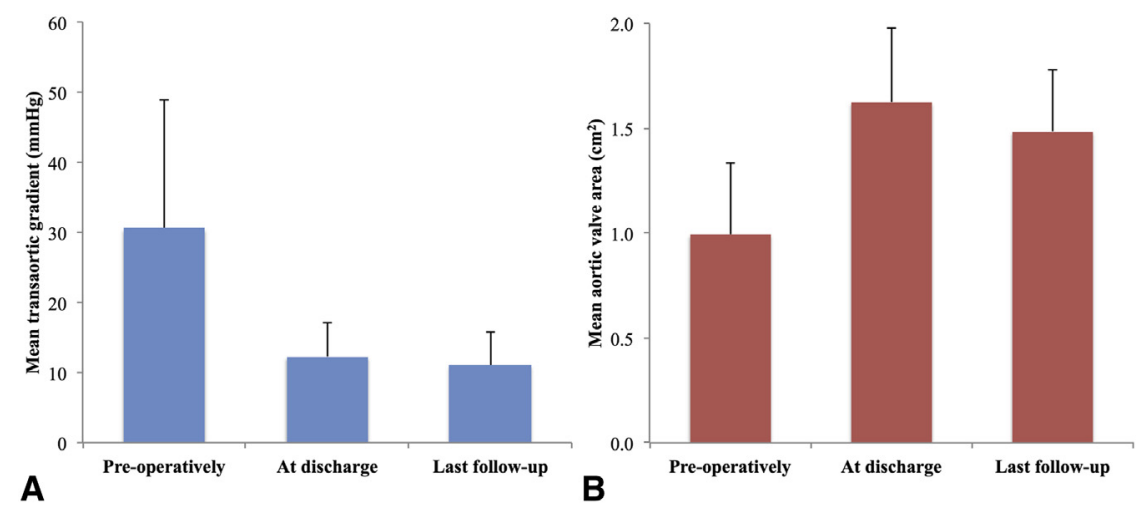

FIGURE 1. Stability of hemodynamic parameters at early follow-up. A, Evolution of mean transaortic pressure gradients. B, Evolution of mean aortic valve area. 

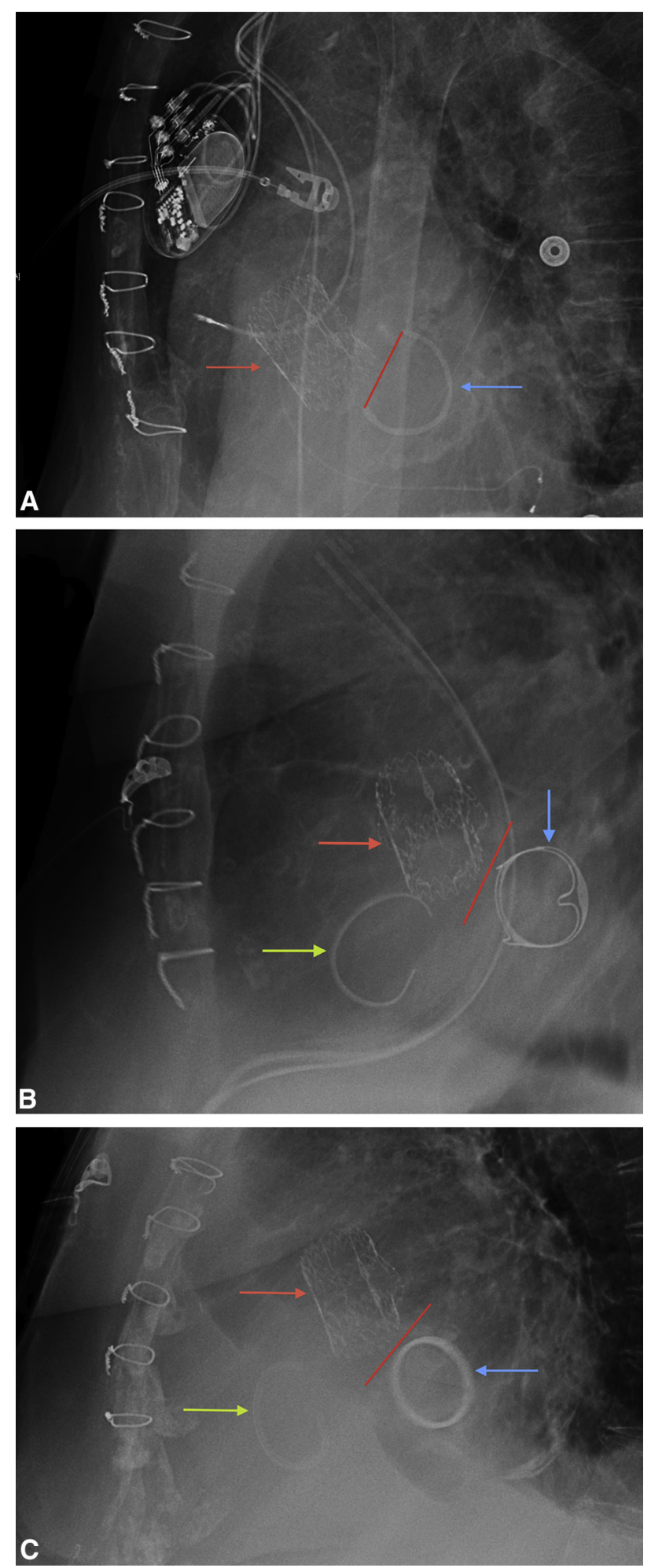

FIGURE 2. Postoperative lateral chest radiographs showing the absence of interference between the Perceval S and mitral prostheses. A, Sorin Annuloflex partial ring for mitral annuloplasty. B, Carpentier-Edwards Perimount Magna Mitral Ease bioprosthetic valve. C, Sorin Carbomedics mechanical mitral prosthesis. The blue arrow points to the mitral prosthesis. The red arrow points to the Perceval aortic sutureless bioprosthesis. addition, sutureless AVR is performed under direct vision, which allows more precise positioning of the prosthesis.

Although procedural success was achieved in all patients, intraoperative redeployment of the sutureless valve was selectively required. In 2 cases, this was due to a large annular size precluding tight implantation of the sutureless ring. Reduction aortic commissuroplasty was thus performed with perfect valve competence. Since these procedures, the extralarge Perceval prosthesis $(27 \mathrm{~mm})$ has been introduced, which would have prevented the initial problem. The 2 remaining cases of redeployment were caused by malpositioning of the prosthesis in a supraannular position, which is recognized when the native aortic annulus can be seen through the opened prosthetic leaflets (after final dilation with the balloon). Possible causes of malposition include (1) incorrect visualization of the annulus nadir, (2) inadequate angulation of the delivery system, (3) excessively rapid release of the prosthesis, and/or (4) aortic device shift during balloon inflation. Valvuloplasty balloon shift caused by a rigid mitral prosthetic strut has been described in patients with functioning mitral prostheses undergoing $\mathrm{TAVI}^{8}$ However, it is unlikely that the 2 cases of supraannular malposition described in this series were the result of device shift during balloon inflation. The balloon used for sutureless AVR is much shorter than the one used in TAVI and thus protrudes much less in the LVOT. The risk of contact with the mitral prosthesis is therefore minimal. In addition, during balloon inflation, the sutureless aortic device is maintained in place by its specific holding device.

In this series, the cases requiring redeployment were performed at the beginning of our sutureless AVR experience and are mainly attributable to the learning curve. Removal of the prosthesis using the $\chi$-movement technique $^{6}$ is easy and reproducible without damaging the valve or the nitinol structure. This is performed by holding the superior portion of the nitinol stent at 2 opposite points and dragging them to the center of the prosthesis. This procedure is simple, reproducible and can be performed in less than 5 minutes, thus minimally affecting the length of the operation.

\section{Mitral Annuloplasty}

The choice of prosthesis for mitral annuloplasty should aim to minimize the risk of interference with the sutureless aortic valve while ensuring a perfect repair. The preferred approach in this series was the use of the Annuloflex partial ring because its semicircular design allows preservation of the three-dimensional conformation of the aorto-mitral curtain.

\footnotetext{
The green arrow points to a tricuspid annuloplasty ring. The red line shows the absence of contact between the Perceval aortic sutureless bioprosthesis and the mitral prosthesis.
} 


\section{Biological MV Replacement}

Bioprostheses have prominent commissural struts that may partially project into the LVOT. The preferred mitral bioprosthesis in this series was the Edwards Magna-Ease because of its low profile design and its asymmetric shape that minimizes protrusion of the struts into the LVOT. It is also important that, at the time of MV replacement, the commissural struts be positioned away from the aortomitral continuity to minimize the risk of interference with the infraannular portion of the sutureless aortic prosthesis. In addition, when suturing the MV, great care must be taken to avoid shrinking at the level of the noncoronary sinus, because this may alter the dimensions of the aortic annulus. Final sizing of the Perceval prosthesis should be performed after completion of the MV replacement.

\section{Mechanical MV Replacement}

In the context of reoperation, a patient who is a candidate for sutureless AVR may have a functioning mechanical mitral prosthesis in place. This was the case in 1 patient in this series who had undergone a mechanical MV replacement 21 years earlier with a Carbomedics valve. The presence of a mechanical MV is less problematic for sutureless AVR than the presence of a bioprosthesis because of the absence of commissural struts. In addition, the Carbomedics valve has a very low profile design, which further minimizes its protrusion into the LVOT. However, the feasibility of sutureless AVR in the presence of a previously implanted cage and ball mechanical mitral prosthesis such as the Starr-Edwards valve remains unknown. Implantation of a sutureless aortic prosthesis in this setting may raise concern due to the specific design of this prosthesis in which a large segment of the cage protrudes into the LVOT.

In the present series, the rate of perioperative complications was low, especially considering this high-risk population. The rate of postoperative requirement for a permanent pacemaker because of complete atrioventricular block $(20 \%)$ seems higher than expected but the cohort size is too small to draw any conclusions. The hemodynamic results were excellent on the predischarge echocardiograms and stable at follow-up, with low transaortic gradients, absence of paravalvular leak, and no evidence of mitral dysfunction. The overall survival at 8 months was $80 \%$ with no valve-related mortality. Clinical evolution in surviving patients was excellent with a return to NYHA functional class I in 7 of 8 patients.

\section{Study Limitations}

The main limitation of this report is the relatively small sample size. Further studies will be needed to confirm our findings, especially with regard to the redeployment rate and postoperative need for a permanent pacemaker. In addition, long-term clinical and echocardiographic follow-up is warranted to assess the durability of this procedure.

\section{CONCLUSIONS}

This is the first case series describing sutureless AVR performed in patients with concomitant mitral disease. In our experience, sutureless AVR in this setting is a feasible and reproducible procedure, yielding excellent clinical and hemodynamic results. As elderly patients undergoing multiple valve surgery present a higher operative risk, extending the indication for sutureless AVR to patients with concomitant mitral disease could significantly benefit this specific patient population.

\section{References}

1. Eichstaedt HC, Easo J, Harle T, Dapunt OE. Early single-center experience in sutureless aortic valve implantation in 120 patients. J Thorac Cardiovasc Surg. 2014;147:370-5

2. Flameng W, Herregods MC, Hermans H, Van der Mieren G, Vercalsteren M, Poortmans G, et al. Effect of sutureless implantation of the Perceval S aortic valve bioprosthesis on intraoperative and early postoperative outcomes. J Thorac Cardiovasc Surg. 2011;142:1453-7.

3. Ranucci M, Frigiola A, Menicanti L, Castelvecchio S, de Vincentiis C, Pistuddi V. Aortic cross-clamp time, new prostheses, and outcome in aortic valve replacement. J Heart Valve Dis. 2012;21:732-9.

4. D’Onofrio A, Messina A, Lorusso R, Alfieri OR, Fusari M, Rubino P, et al. Sutureless aortic valve replacement as an alternative treatment for patients belonging to the "gray zone" between transcatheter aortic valve implantation and conventional surgery: A propensity-matched, multicenter analysis. J Thorac Cardiovasc Surg. 2012;144:1010-6.

5. Alsoufi B, Rao V, Borger MA, Maganti M, Armstrong S, Feindel CM, et al. Short- and long-term results of triple valve surgery in the modern era. Ann Thorac Surg. 2006;81:2172-7; discussion 2177-8.

6. Santarpino G, Pfeiffer S, Concistre G, Fischlein T. A supra-annular malposition of the perceval sutureless aortic valve: the 'chi-movement' removal technique and subsequent reimplantation. Interact Cardiovasc Thorac Surg. 2012;15: 280-1.

7. Magover GJ, Cromie HW. Sutureless prosthetic heart valves. J Thorac Cardiovasc Surg. 1963;46:726-36.

8. Soon JL, Ye J, Lichtenstein SV, Wood D, Webb JG, Cheung A. Transapical transcatheter aortic valve implantation in the presence of a mitral prosthesis. J Am Coll Cardiol. 2011;58:715-21.

9. Drews T, Pasic M, Buz S, Unbehaun A, Dreysse S, Kukucka M, et al. Transapical aortic valve implantation after previous mitral valve surgery J Thorac Cardiovasc Surg. 2011;142:84-8.

10. Bruschi G, De Marco F, Barosi A, Colombo P, Botta L, Nonini S, et al Self-expandable transcatheter aortic valve implantation for aortic stenosis after mitral valve surgery. Interact Cardiovasc Thorac Surg. 2013;17:90-5.

11. Bruschi G, De Marco F, Oreglia J, Colombo P, Barosi A, Einaudi A, et al. Transcatheter self-expandable aortic valve implantation after undersized mitral annuloplasty. Ann Thorac Surg. 2011;92:1881-3.

12. Rodes-Cabau J, Dumont E, Miro S, Doyle D, De Larochellière R, Clavel MA, et al. Apical aortic valve implantation in a patient with a mechanical valve prosthesis in mitral position. Circ Cardiovasc Interv. 2008;1:233.

13. Testa L, Gelpi G, Bedogni F. Transcatheter aortic valve implantation in a patien with mechanical mitral prosthesis: a lesson learned from an intraventricular clash. Catheter Cardiovasc Interv. 2013;82:E621-5.

14. Beller CJ, Bekeredjian R, Krumsdorf U, Leipold R, Katus HA, Karck M, et al. Transcatheter aortic valve implantation after previous mechanical mitral valve replacement: Expanding indications? Heart Surg Forum. 2011;14:E166-70. 